\title{
The development of an objective method for evaluating transient sleeping environments
}

\author{
Olga Troynikov*, Nazia Nawaz, Christopher Watson \\ From 15th International Conference on Environmental Ergonomics (ICEE XV) \\ Portsmouth, UK. 28 June - 3 July 2015
}

\begin{abstract}
Introduction
Poor sleep is the key sleep attribute that affects the overall recuperative quality of the sleep state [1]. A common approach in human sleep testing is to use subjects in an environmental chamber [2-4]. One of the significant limitations of this testing is its subjectivity and the small number of subjects [5]. The use of thermal manikins to measure thermal and vapour resistance is a standard method adopted for assessment of sleeping bags and has also been used to measure these attributes of a range of bedding systems, as well as different sleepwear [6].
\end{abstract}

\section{Methods}

A compacted transient experimental protocol totalling 3 hours 20 minutes was established in order to determine the possible impact of the different bedding systems and mattresses on sleeping bedding microclimates, using a 20 zone sweating thermal manikin, Newton. A dynamic experimental cycle of different heating and sweating phases was used to simulate the sleeping human metabolic and sweating activity conditions through different sleep phases. The manikin was placed on the experimental mattress, either latex or inner spring, in the experimental bedding systems in a controlled environmental chamber. Temperature and humidity in the next to skin microenvironment were dynamically measured at different sites of the manikin's body by using temperature and humidity sensor arrays. The environmental temperature was set at $17^{\circ} \mathrm{C}$, and a relative humidity rh was set at $50 \%$. All individual elements of the sleeping systems were conditioned prior to each experiment in the climatic chamber at the relevant test conditions of $17{ }^{\circ} \mathrm{C}$ and rh of $50 \%$ for 12 hours.

\footnotetext{
* Correspondence: olga.troynikov@rmit.edu.au

Human Ecology and Clothing Science Research Group, School of Fashion and Textiles, RMIT University, Melbourne, Australia
}

\section{Results}

The study found that the latex mattress ensemble exhibits a higher overall bedding micro environmental temperature than the inner spring mattress ensemble with all other variables being constant. This resulted in up to $3{ }^{\circ} \mathrm{C}$ higher micro environmental temperature for all bedding systems by the end of the experiment. Furthermore, the micro environmental temperature differences between the front and the back zones of the manikin for the latex mattress reach $2.5^{\circ} \mathrm{C}$. The latex mattress ensemble also exhibits higher overall microclimate humidity levels in comparison to the inner spring mattress ensemble, with all other variables being constant, with humidity levels for the back zones being double for the latex ensemble in comparison to the inner spring ensemble and reaching $50 \% \mathrm{RH}$. In particular, the humidity levels for the microclimate at the back zones of the manikin are significantly higher for the latex system in comparison to the inner spring mattress system. Both Independent sample $t$-test of experimental data and Paired Samples Statistical analyses of data produced $\mathrm{p}$-values less than 0.05 . This allowed the conclusion that there is a significant difference between micro environments produced by the experimental bedding systems and mattress ensembles.

\section{Conclusion}

The developed objective method and exploratory initial experimental results of this study suggest that it is possible to objectively identify bedding systems which provide moderate micro environmental temperature fluctuations and steady humidity profiles during the sleep cycle.

Published: 14 September 2015 


\section{References}

1. Paterson Louise M: The Science of Sleep: What is it, what makes it happen, and why do we do it? In in Sleep: Multi-professional Perspectives. Jessica Kingsley Publishers;Alex Westcombe, and Andrew Green 2012:

2. Okamoto-Mizuno Kazue, Koh Mizuno: Effects of thermal environment on sleep and circadian rhythm. J Physiol Anthropol 2012, 31(1):14.

3. Lee Hyunja, Sejin Park: Quantitative effects of mattress types (comfortable vs. uncomfortable) on sleep quality through polysomnography and skin temperature. International journal of industrial ergonomics 2006, 36(11):943-949.

4. Leung Chris, Hua Ge: Sleep thermal comfort and the energy saving potential due to reduced indoor operative temperature during sleep. Building and Environment 59(2013):91-98.

5. Henane R, et al: Variations in evaporation and body temperatures during sleep in man. Journal of Applied Physiology 1977, 42(1):50-55.

6. Lin Zhongping, Shiming Deng: A study on the thermal comfort in sleeping environments in the subtropics-Measuring the total insulation values for the bedding systems commonly used in the subtropics. Building and Environment 2008, 43(5):905-916.

doi:10.1186/2046-7648-4-S1-A141

Cite this article as: Troynikov et al:: The development of an objective method for evaluating transient sleeping environments. Extreme

Physiology \& Medicine 2015 4(Suppl 1):A141.

\section{Submit your next manuscript to BioMed Central} and take full advantage of:

- Convenient online submission

- Thorough peer review

- No space constraints or color figure charges

- Immediate publication on acceptance

- Inclusion in PubMed, CAS, Scopus and Google Scholar

- Research which is freely available for redistribution

Submit your manuscript at www.biomedcentral.com/submit 